\title{
Study on Duality Creation of Margaret Atwood 's The Blind Man
}

\author{
Xin $\mathrm{Li}^{1, \mathrm{a}}$ \\ ${ }^{1}$ Luohe Medical College, Luohe, Henan, 462000 \\ ${ }^{a}$ email
}

Keywords: Dualism, Blind Assassin, Narrative Structure, Feminism

\begin{abstract}
Duality is one of the important features of Margaret Atwood's overall creation. His novel "Blind Killer" (also translated as "Blind Assassin") makes the duality more complicated and pluralistic through the narrative structure of "Chinese Boxing", which manifested as personal memory and public memory, false and true, history and fictitious three groups of unity of opposites. From the narrative structure, based on the thorough reading of the text and the analysis of feminism, this article analyzes the dual characteristics of the "blind assassin" and finds out that Atwood's unique narrative structure reveals the hidden and true living conditions of the female.
\end{abstract}

\section{Introduction}

Atwood's Sherill Grace, in his book The Violent Duality: Margret Atwood 1980, points out that duality is one of Atwood's overall features. The so-called duality is the contradiction between opposites and unity.

Whether poetry or novels, they are implicitly or significantly reflects the duality of Atwood's perspective. But in his tenth novel The Blind Assassin, the duality is not only obvious, but also because of the use of the narrative structure of the Chinese set of boxes (called "Russian Dolls"), compared to Atwood Previous works are more unique and thick.

The contradictory relationship between these three groups, which is both contradictory and unified, constitutes a rich and complex duality of the "blind assassin". Li Xiangping in Liang Qiaona "gender consciousness and female image" in the preface of the book of feminist criticism as "left-handed" thinking, and Atwood also declared that "blind assassin" is a book written by the left hand, in fact, are In showing that women's way of thinking and the existence of a different from the habit of using the "right hand" the existence of male society. Atwood in the "blind assassin" in the use of "Chinese box" type of narrative structure, reflecting the complex and diverse duality, secretly reflects the true existence of women and ways of thinking. Here I will analyze one by one the duality of these three groups, which reveals how Atwood's "left hand" to reveal women as "left" writing.

\section{Personal Memory and Public Memory}

Although the "blind assassin" is difficult to define it with the traditional genre, but its subject is a memoir, so from the content of this is a novel about the memories. Alice's memories belong to the individual, private and constitute the personal memory of this article. But this is not a pure memoir, Atwood in his novel ingenuity to rub into the news reports. Objectively, news newspapers constitute a family history of public memory, so it can be said that news clippings constitute the public memory of this article. They form two sets of memory system, not only each other, but also with each other.

Public memory provides clues to personal memory, as the translator Han Zhonghua said in the translation: "The authors through the clippings to reflect the clues of the story, and they and the whole story organically together, and the integration was seamless.

The first category: death obituaries, including the Toronto Star (1945), the Globe and Mail (1947, The Toronto Star (1975, Globe and Mail (1998). Blind Assassins are flooded with Death Message and Unsolved Mystery. "On the tenth day after the end of the war, my sister Laura drove down the bridge, which was the first sentence of the" Blind Assassin, "which immediately aroused the 
reader's guess: (1945) reported that the death of Laura, and attributed the cause of death to poor road management, apparently the answer is more worrisome. However, the death of Laura, Laura died

The mystery has not yet cracked, the author inserted in the text of the signature "Laura Chase" and "Blind Assassin" introduction, unknown name "she" took out the collection of photos, carefully staring at it, looking for " A thing she lost. " Since then, the first chapter of the work is over. In this chapter, the author opens three narrative clues: narrator's self-report, clippings and the same name novel "blind assassin". The next chapter, the author continues the same name novel "blind assassin" story, while interspersed with four news clippings. The first, second, and third were the death obituaries of Richard, Aime Griffin, and Winifred Griffin Pryor. What is linked to this series of death obituaries, the answer is Alice - Laura's sister, Richard's wife, Aime's mother, Wei Nifu Lei De's wife. She is the only survivor, only she knows the story behind these deaths. Knowing that there was not much time, she picked up the pen began to untangle the complex relationships behind the many characters.

Class II: Clippings from transitional roles, including "The Clippings of the High School Home of Henry P. Parkman" (1998). The above mentioned in the second chapter and the novel of the same name "blind assassin" parallel to the start of the four news clippings, the first three is the death obituary, the above has been discussed. The fourth item is different, it is "Laura Chase Memorial Award" upcoming news. The newspaper clippings served as a bridge between Laura Chase and the legacy of the death of the Vonnie Fred, referred to in the third press clippings, Of the sister Alice to issue. Thus, the author of the third chapter below writes of Alice's participation in the ceremony of the love Laura Chase commemoration, bringing the reader to the time-space environment in which Alice, an 82-year-old, lives in 1998. This award was awarded to tear her deep wound for many years, she took a year to record the memories of her life experience

(1933), the Empire Post (1933), the Empire Post (1933), Mayfair (1935), the United States of America and the United States of America, (1936), Mayfair (1937), The Post Office (1936), The Mayflower (1936), The Mailing House , "Globe and Mail" (1938), "Mayfair" (1939) .This kind of clippings time concentrated in the 1930s, this period is Alice memory of the most profound,

The most far-reaching impact on her period is defined this period as a special period of newspaper clippings. The fourth chapter refers to four clippings, the contents are: the first March 16, 1933 "Ticonderoga Port Herald flag" reported the national economic depression, Alice's father as an entrepreneur to the disaster-stricken Article 2 The Empire Post reported on December 5, 1934, that in the midst of the economic depression, domestic turmoil, President of the Royal Knitting Company, Richard, commended President Bennett's "ruthless iron-shoe" policy; Three December 1934 or the "Empire Post" reported in Ticonderoga port of violence; the fourth on behalf of the fashion trend of "Mayfair" magazine in May 1935 reported Alice and the rationale Chad's engagement ceremony. The next five chapters continue to narrative person Alice's memories, and memories of the time and content just in the fourth chapter of the newspaper clipping time and content. Similarly, the time and content of clippings in Chapters 6, 8, 10, and 12 form a corresponding relationship with Alice's readings in Chapters 7, 9, 11, and 13. Therefore, it may be

To arrive at the conclusion that the clippings of these special periods provide Alice's readings with historical background and corroboration, and inform the narrative clues of the narrator in advance.

The fourth category: as the closing clippings, including "Ticonderoga Port Herald" (1999). In the final chapter of the work, the time came in 1999, that is, Alice died that year, "Ticonderoga Port Herald Flag" reported Alice's death. At this point, the whole work to the death of Laura's news began, and the death of Alice's news reports end, for the history of painting a successful conclusion.

In summary, as a public memory of the news clippings through the author's carefully arranged in the text as early as Alice's readme, for Alice's narrative provides a time-space clue. While the public memory in the personal memory of the reference to show the false side. In public memory, Alice lived in a decent warm atmosphere of the family, is the envy of high society lady. The personal memory of Alice in order to save his father's business was "sold" to Richard, and in marriage is just 
an ornament, to meet Richard's vanity, but also vent to play Richard's sexual desire. At the same time in her lady's life under the surface, but also with the left-wing young Alex secretly tryst, lived an unknown double life. Similarly, personal memory of Laura, Richard, Wei Nifu Lei De is not in public memory as it is.

The author explores the multiple ways of memory in novels. The novel not only accommodates the memory of the narrator Alice's present and past, but also accommodates the memory of the individual and the public, and shows the possibility of multiple interpretations of the same story. The author puts Alice's personal memory in the historical background of the 20th century. While showing the public memory and the important scenes, Alice reveals the false and blindness of public memory, and the irony of historical narration. The extent of the show has the real power. Personal memory in the grand history of the narrative issued a weak voice, but also on the patriarchal society to suppress the persecution of female cultural roots of the search and reflection.

\section{False Me and Real Me}

Alice's novel and her novel "Blind Assassin" reflect the dual lives of the noble lady and the "slut" with the revolutionary party. They represent the duality of Alice's fake and true self.

Alice's content, although the first person to "I" started the story, but in fact it is "fuzzy features" and "upper-class prettily bride", obliterate the personality of the "family angel." Atwood in the use of Alice's name reflects the intention. In English, Iris refers to the eye mask, can be used to refer to the eyes, and Iris and eyeless (eyeless and blind) and I-less (no self) homophonic. Alice in the readme to show the blind and the lack of self, the blind and not self

Alice I call it false. In the same name novel "Blind Assassin" Alice rebellious, passionate, although to the third person "her" narrative, but "she" is independent, subject to the inner feelings of their own way against the hypocrisy of marriage Life, "she" is Alice's true me. The reason why Tolaola name, according to Alice's explanation is because Laura is her spiritual partner, that Lara is actually another Alice's self.

Although Alice has been obedient to the patriarchal society of her transformation, is an "open-eyed sleepwalker", but in the heart of her independence and freedom have a deep desire. As a child, she studied the alphabet. Laura liked the letter L, because it was the first letter of her name, and Alice did not like the beginning of her name, because the first letter of her name was the letter of everyone. This detail reveals in Alice's subconscious and Laura as free, rebellious. It also laid the seeds for Alice's transformation from falsehood to truth.

Laura as the opposite of Alice and the spirit of the mentor exists, and guide Alice gradually recognize self "blind assassin" (male social complicity) situation and to resist the road. However, this guide is a tragic death is completed. Laura's suicides had a huge impact on Alice. She opened Laura's digital notes and saw the number and date behind Richard's bodily injury to Laura. She read Laura's color code, the color represents the soul of beauty and ugliness, Richard and Winifred's red and green hate, on behalf of their evil, evil; Alice's blue and white show Her blindness and loss of self; Laura yellow that she was not understood, seeking understanding of the state, but also represents the light and hope, suggesting that she will eventually lead the Alice from the blind to a sober light.

After reading Laura's notes, Alice "Everything is clear." Here, "everything is clear," meaningful, not only on behalf of Alice on Laura encounter clear, but also refers to her own "blind assassin" situation clear. Blind to their insight for Alice is to the courage to act, the patriarchal society to her transformation to give her the wisdom to fight back. In her sister's two years after death, she published in Laura's name to her and Alex's secret romance as the content of the "blind assassin", causing public investigation of the death of Laura, Richard In the end, eventually led to his suicide.

Laura incident, Alice spent decades in his hometown appearance of normal life. But with the passage of time, she began to sleep at night, gradually realized that the silence of the error, Alice finally broke the silence with a pen to record the former dust. Writing has become a way of Alice to obtain a calm conscience, but also with a pen and soul for the presence of Laura witnessed. In the process of writing, Laura is an opening on the missing aphasia, but always lingering in the narrative 
story. In the process of self-analysis, Alice and Laura as the soul of communication, she more and more experience

To Laura is in fact she has been suppressed with another self. This is why Alice said, "Laura is my left hand, I am also her left hand, we write the book together, this is a left-handed book." "Atwood, in his left hand and right hand, writes: 'The left hand, as you see it, weak and slim,' but 'right hand holding a knife and dancing at the left hand' (Atwood, Two- Headed Poems56) The right hand in Atwood 's world represents the male-dominated existing order, while the left

Hand is as vulnerable groups, but the presence of creative women's thinking. In this left-handed book, Alice completed with Laura from the departure to the identity of the process, that Alice also completed their own from false to true unity.

By comparing Alice's novel with the novel "Blind Assassin", Atwood shows a woman's dual self in the male-dominated social ideology. Atwood's unique feature is that she not only reveals the patriarchal society to shape and abuse of women, but also criticized the blind side of the male society of women. Through Alice's memories can be seen, the reason why women have been suppressed, male society is the fundamental reason, but by no means the only reason, women should find their own answers. Alice's self-statement represents a reflection of attitude, with a painful reflection to inspire the majority of women to eliminate their blindness. This is the way women survive, but also a prerequisite for women to seek liberation.

\section{History and Fiction}

Alice's statement over more than a century, about the history of Canada more than 100 years of style, including two World War, the Great Depression and other major historical events. These are realist histories. But in the novel "Blind Assassin", the story in the story is only a fictional story, but it has a metaphorical relationship with the historical reality of Alice's life. If Alice's memoir is "real" in the historical sense, the science fiction in Blind Assassin should be another kind of "real" - fictional reality. Although it is fictional, everywhere and Alice live modern Canadian reality and her personal life experience to form a corresponding relationship. The fictional city of Sarkino is Alice in the real one of Canada. Saginaw City is a hierarchical society, full of oppression and oppression of the struggle. Here, when Alice suspected the rise of Bolshevism, the science fiction of the fabricator Alex retorted:

"My description is from the ancient Mesopotamian culture, and there is a similar provision in the Hammurabi Code and the Laws of the Hittites. This shows that the story of Saginaw City is not nonsense, it has historical basis, but also coincides with the then Canada and the whole world situation. In the thirties of the twentieth century in Canada and the whole world, the class struggle surging, labor conflicts sharp, triggering a wave of strikes workers, Alice's family business in this context precarious. The characters in the city of Sarkino correspond to Alice's characters. Saginaw City sacred offerings are the reality of Alice and Laura. In the city of Sarkino, the noble class to maintain their noble status must be the daughter as a sacrifice to the gods. In order to prevent the sacrifice shouting, they cut off the sacrifices of the tongue, holy virgin became unable to speak of the victim. In reality, Alice's father in order to save the family business, like Alice to marry sinister vicious careerist Richard, Alice became a "prettily the bride of high society." After the death of his father, Laura moved to live with her sister, Richard to the young spear of Laura, Laura to their own minds of the "gods" - Alex's safety, and Richard Germany reached a "tripartite transaction" to physical protection in exchange for the safety of Alex. Alice and Laura, respectively, for the family and love sacrifice. Richard is the city of Sarkino in the seizure of wealth, the Sinifa aristocrat wife.

Sarkino city blind assassin and the dumb woman love story is Alex and Alice love metaphor. In a conspiracy to assassinate the assassination of action, the blind assassin and dumb female met, through the most primitive physical contact, they fell in love. So things from the original plan of the track, blind assassin betrayal of the assassination action with a dumb girl escaped from the city of Sarkino. Alice is a high society ladies, nature is patriarchal society sacrifice, to save the family business willing to go to the altar. Alex is a socialist youth, is opposed to the current unreasonable social system of left-wing forces, his appearance on the long-term imprisonment in the "high-rise" 
in the Alice is undoubtedly a rescue force.

As the work draws to a close, Alice writes, "Wolves, I pray to you, The ghosts with sky-blue hair and breathtaking big eyes, I summon you! ... My partner, my helper, My friend; I said help me again, are we not very familiar with it in the past? "Alice for the first time in the text of the self-described the use of science fiction images, since the history and fiction to achieve the fusion, Namely history.

To sum up, Alice on the family and personal history readme and the "story of the story" formed a dialogue. The story in the story depicts the feminine culture in the aristocratic class society. On the one hand, Alice's society is sharply criticized and exposed. On the other hand, attention is paid to the endless repetition of class struggle and female violence.

\section{Conclusion}

Although Atwood did not act as a feminist, she was clearly aware of the importance and particularity of female identity in writing at the outset of her writing career. In the practice of writing, Atwood is also concerned about the survival of women, closely around the "growing female consciousness of the basic motif", "blind assassin" permeated Atwood profound feminist consciousness and her narrative strategy and feminist consciousness are closely linked to achieve the effect of using the form to convey the theme. "Left hand" relative to "right hand" is the existence of neglect, is a kind of edge of the existence. "Blind Assassin" is a book written with his left hand, the author is different from the mainstream of the right to speak with the narrative strategy of men as silent and marginalized women "left-handed" state of existence. Atwood used the corresponding narrative strategy to construct the history which belongs to the women.

\section{References}

[1] Mary Atwood. Blind Assassin [M]. Han Zhonghua, translation. Shanghai: Shanghai Translation Publishing House, 2007: Translating 1-425-12-410

[2] Guo Guoliang, Zhao Jie. The Existentialist Intervention in "Blind Assassin" [J]. Foreign Literature Studies, 2006 (5): 118

[3] Margaret Atwood. Blind Assassin [M] .Toronto: McClellandand Stewart, 2000

[4] Fu Jun. Margaret Atwood Research [M]. Nanjing: Yilin Publishing House, 2003

[5] Ke Qianting. "Blind Assassin": a novel about memory [J]. Foreign Literature Review, 2007 (1) 